Article

\title{
Biological and Genetic Heterogeneity in Trypanosoma dionisii Isolates from Hematophagous and Insectivorous Bats
}

\author{
Juliana Helena da Silva Barros ${ }^{1, *}$, André Luiz Rodrigues Roque ${ }^{1}$ (I), \\ Samanta Cristina das Chagas Xavier ${ }^{1}$, Kátia Cristina Silva Nascimento ${ }^{1}$, Helena Keiko Toma ${ }^{2}$ \\ and Maria de Fatima Madeira ${ }^{3}$ \\ 1 Laboratório de Biologia de Tripanosomatídeos, Instituto Oswaldo Cruz, Fundação Oswaldo Cruz, \\ Rio de Janeiro 21040-360, Brazil; roque@ioc.fiocruz.br (A.L.R.R.); samanta@ioc.fiocruz.br (S.C.d.C.X.); \\ katiacristh@gmail.com (K.C.S.N.) \\ 2 Laboratório de Diagnóstico Molecular e Hematologia, Faculdade de Farmácia, Universidade Federal do Rio \\ de Janeiro, Rio de Janeiro 21491-599, Brazil; hktoma@globo.com \\ 3 Laboratório de Vigilância em Leishmanioses, Instituto Nacional de Infectologia Evandro Chagas, \\ Fundação Oswaldo Cruz, Rio de Janeiro 21040-360, Brazil; fatima.madeira2@gmail.com \\ * Correspondence: juliana.barros@ioc.fiocruz.br; Tel.: +55-21-2562-1416; Fax: +55-21-2562-1609
}

Received: 31 July 2020; Accepted: 26 August 2020; Published: 7 September 2020

\begin{abstract}
This study describes the morphological, biochemical, and molecular differences among Trypanosoma dionisii isolates from hemocultures of hematophagous (Desmodus rotundus; $n=2$ ) and insectivorous (Lonchorhina aurita; $n=1$ ) bats from the Atlantic Rainforest of Rio de Janeiro, Brazil. Fusiform epimastigotes from the hematophagous isolates were elongated, whereas those of the insectivorous isolate were stumpy, reflected in statistically evident differences in the cell body and flagellum lengths. In the hemocultures, a higher percentage of trypomastigote forms (60\%) was observed in the hematophagous bat isolates than that in the isolate from the insectivorous bat (4\%), which demonstrated globular morphology. Three molecular DNA regions were analyzed: V7V8 (18S rDNA), glycosomal glyceraldehyde 3-phosphate dehydrogenase gene, and mitochondrial cytochrome $b$ gene. The samples were also subjected to multilocus enzyme electrophoresis and random amplified polymorphic DNA analysis. All isolates were identified as T. dionisii by phylogenetic analysis. These sequences were clustered into two separate subgroups with high bootstrap values according to the feeding habits of the bats from which the parasites were isolated. However, other T. dionisii samples from bats with different feeding habits were found in the same branch. These results support the separation of the three isolates into two subgroups, demonstrating that different subpopulations of $T$. dionisii circulate among bats.
\end{abstract}

Keywords: Chiroptera; trypanosomatid; Schizotrypanum; integrative methodologies; molecular characterization; biological characterization; differences among isolates

\section{Introduction}

Trypanosomatids are widely distributed in nature and according to the number of hosts participating in their biological cycle, are classified as monoxenous (one host) or dixenous (two or more hosts) [1]. Due to its wide morphological diversity, its taxonomic classification has always been a challenge, since traditional morphological and biological studies, to the current integration with genomics analysis and improvements in microscopy approaches [2]. Among the different genera of the Trypanosomatidae family, the Trypanosoma genus includes species that are found in all classes of vertebrate hosts. The protozoan Trypanosoma dionisii is a parasite found in the Americas (Brazil, Bolivia, 
and the United States), Europe (Belgium, England, and Czech Republic), and Asia (China and Japan) [3-9]. In Brazil, T. dionisii is found in almost all biomes, including the Amazon, Atlantic Forest, Cerrado, Pantanal, and transition areas of the Pantanal and Cerrado. The protozoan infects different bat families, including Phyllostomidae, Molossidae, Noctilionidae, and Vespertilionidae in various regions from northern to southern Brazil [4,10-13].

For many decades, $T$. dionisii was considered restricted to bats and believed to be transmitted only by Cimicidae, which acts as a vector [14-16]. Recent studies have shown that T. dionisii is not restricted to only bats; it also infects different mammalian hosts and vectors, including human cardiac tissue [17], Carnivora clot blood [18], the Didelphimorphia [18] species, and the digestive tract of the triatomine, Triatoma vitticeps [17]. These recent descriptions demonstrate that very little information is available about the dynamics of the transmission cycle of this parasite in nature, and the hosts and vectors involved.

T. dionisii is categorized into the Trypanosoma cruzi clade with other species of the subgenus Schizotrypanum, such as Trypanosoma cruzi cruzi, Trypanosoma cruzi marinkellei, and Trypanosoma erneyi. In fact, $T$. dionisii was referred to as T. cruzi-like for many decades due to its morphological similarity in terms of blood and cultured forms to T. c. cruzi [14]. Both T. dionisii and T. c. cruzi can invade mammalian cells [19] and alternate developmental forms between hosts, with epimastigotes and metacyclic trypomastigotes appearing in the invertebrate host and bloodstream trypomastigotes and amastigotes found in the mammalian host during the life cycle [16,19-21].

Studies evaluating the biochemical and biological characteristics of T. dionisii have been undertaken for many decades [22-24], and current research focuses on identification and phylogenetic analysis. A number of genetic markers, such as ribosomal RNA gene (rDNA) regions (18S and internal transcribed spacer (ITS)), glycosomal glyceraldehyde 3-phosphate dehydrogenase gene (gGAPDH), and mitochondrial cytochrome $b$ gene $(C y t b)$, can be used for genetic analyses of $T$. dionisii $[4,5,25-27]$. Previous studies have focused on recognizing T. dionisii genotypes solely on the basis of molecular data [28]. In this study, integrated analysis of morphological and biochemical (as complementary elements) characteristics, along with molecular data, played an important role in the characterization of Trypanosoma species, especially to identify intraspecific differences. These approaches were employed to compare T. dionisii isolates obtained from hemocultures: M1014 and M1015 isolates from hematophagous (Desmodus rotundus) and M1011 isolate from insectivorous (Lonchorhina aurita) bats captured in Rio de Janeiro, Brazil.

\section{Results}

\subsection{Parasite Morphology and Induction of Metacyclogenesis}

Parasites were maintained by weekly passages in Novy, McNeal, Nicolle (NNN)/Schneider's medium and demonstrated extensive polymorphism among the isolates. Isolates M1014 and M1015 were characterized by a large percentage of trypomastigote forms $(60 \%)$ in all three intervals of observation (three, 10 and 17 days). After three and 10 days, the presence of elongated epimastigote forms and absence of rosettes could be observed in the culture. After 17 days, many forms were observed rounded and destroyed. The isolate M1011 presented some different characteristics: after three days, it presented globular (rounded) epimastigote forms and an absence of rosettes; after 10 and 17 days, the majority of forms were rounded and dividing. M1011 was also observed in degenerate forms, with an absence of rosettes, and rare trypomastigote forms (4\%). After metacyclogenesis and induction in Roswell Park Memorial Institute (RPMI) medium, the percentage of trypomastigote forms in the culture moderately increased (13\%).

Epimastigote forms obtained from insectivorous bats (M1011) and cultured for 10 days varied in terms of the size of the parasite body, with an average length of $9.29 \pm 1.89 \mu \mathrm{m}(6.31-12.71 \mu \mathrm{m})$ and size of the free flagellum, with an average length of 9.39 $\pm 2.19 \mu \mathrm{m}(6.49-12.60 \mu \mathrm{m})$. Epimastigote forms from the hematophagous bat (M1014) demonstrated that the parasite body measured $12.97 \pm 2.50 \mu \mathrm{m}$ 
$(6.88-17.76 \mu \mathrm{m})$, and the free flagellum measured $11.99 \pm 2.50 \mu \mathrm{m}(7.66-17.17 \mu \mathrm{m}$; Figure 1). All quantifications of the size of the parasite body and flagellum were in Supplementary Graphic S1. An ANOVA revealed that there were significant differences between body measurement values $(p=0.00000297)$ and flagellum measurements $(p=0.0027)$ between samples M1011 and M1014.

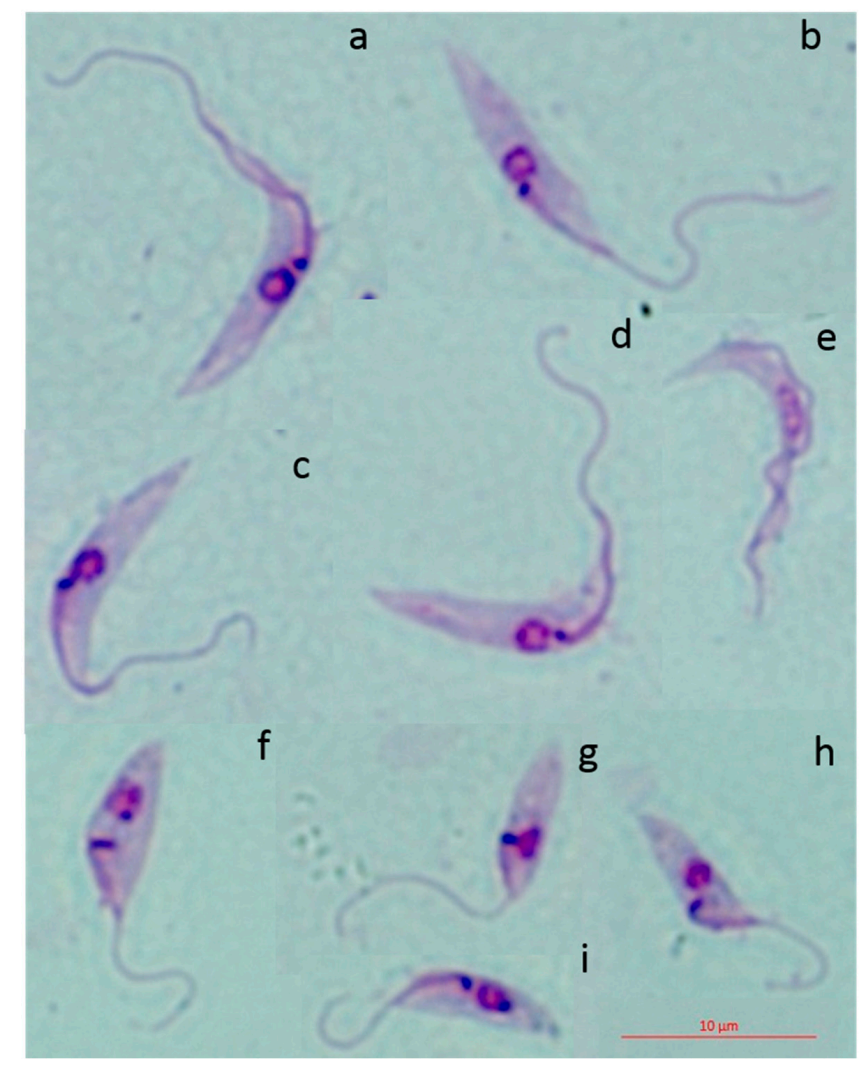

Figure 1. Photomicrographs showing the morphological diversity of cultured forms of $T$ dionisii from hematophagous bat M1014 (a-e) and insectivorous bat M1011 (f-i). Epimastigote forms (a-d,f-i) and trypomastigote form (e).

\subsection{Multilocus Enzyme Electrophoresis}

The banding patterns of the T. dionisii isolates differed in the glucose phosphate isomerase (GPI), malate dehydrogenase (MDH), isocitrate dehydrogenase (IDH), malic enzyme (ME) isoenzymes, with a clear division into two groups: group 1 consisted of the isolate from L. aurita (M1011) and group 2 of the isolates from D. rotundus (M1015 and M1014; Supplementary Figure S1). The other five enzymes analyzed showed no differences among the T. dionisii isolates.

\subsection{Molecular Characterization and Sequencing Analysis}

Sequence analysis of DNA products obtained with the three molecular targets in comparison with DNA sequences of Trypanosoma spp. deposited in Genbank confirmed the identification of the three isolates as T. dionisii (Supplementary Table S1).

Phylogenic analysis based on the three different targets demonstrated that the evaluated isolates clustered (100\% bootstrap) in a monophyletic assemblage with $T$. dionisii species, generating very similar phylogenetic trees. In the T. dionisii clade, the three sequences included in this study were clustered into two separated branches with high bootstraps according to the food habits of the bats in which the parasites were isolated; one branch with the isolate from the insectivorous bat (M1011) and the other with the two isolates from the hematophagous bats (M1014 and M1015). Phylogenetic 
analysis using a combined dataset of V7V8 $18 \mathrm{~S}$ rDNA and gGAPDH (Figure 2) generated similar phylogenetic trees compared to the tree constructed using Cytb sequences (Supplementary Figure S2).

Table 1. GenBank accession numbers of sequences of different genes employed for analyses from different Trypanosoma spp., hosts and geographic origin. * samples from this study. BR-Brazil, BO-Bolivia, MZ-Mozambique, 18S rDNA-small subunit rDNA, gGAPDH-Glyceraldehyde-3-phosphate dehydrogenase, $C y t b$ — cytochrome $b$.

\begin{tabular}{|c|c|c|c|c|c|}
\hline \multirow{2}{*}{$\begin{array}{l}\text { Trypanosoma spp. } \\
\text { Isolates }\end{array}$} & \multirow{2}{*}{ Host Species } & \multirow{2}{*}{ Geographic Origin } & \multicolumn{3}{|c|}{ GenBank Accession Number } \\
\hline & & & 18S rDNA & gGAPDH & Cytb \\
\hline \multicolumn{6}{|l|}{ T. dionisii } \\
\hline M1011* & Lonchorhina aurita & Rio de Janeiro/BR & MH047820 & MN233645 & MH047823 \\
\hline M1014 * & Desmodus rotundus & Rio de Janeiro/BR & MH047821 & MN233646 & MH047824 \\
\hline M1015* & Desmodus rotundus & Rio de Janeiro/BR & MH047822 & MN233647 & MH047825 \\
\hline CBT 116 & Myotis nigricans & Espírito Santo/BR & KF557751 & KF557742 & - \\
\hline CBT 69 & Desmodus rotundus & Espírito Santo/BR & KF557750 & KF557741 & - \\
\hline CBT 66 & Carollia perspicillata & Espírito Santo/BR & KF557749 & KF557740 & - \\
\hline CBT 65 & Carollia perspicillata & Espírito Santo/BR & KF557748 & KF557739 & - \\
\hline CBT 64 & Carollia perspicillata & Espírito Santo/BR & KF557747 & KF557738 & - \\
\hline CBT 63 & Carollia perspicillata & Espírito Santo/BR & KF557746 & KF557737 & - \\
\hline CBT 59 & $\begin{array}{c}\text { Lophostoma } \\
\text { braziliense }\end{array}$ & Espírito Santo/BR & KF557745 & KF557736 & - \\
\hline CBT 58 & Sturnira lillium & Espírito Santo/BR & KF557744 & KF557735 & - \\
\hline P3 & $\begin{array}{l}\text { Pipistrellus } \\
\text { pipistrellus }\end{array}$ & England & AJ009151 & AJ620271 & - \\
\hline X842 & Nyctalus noctula & England & FN599058 & FN599055 & - \\
\hline $\mathrm{MPM}<\mathrm{JPN}>: 21385$ & $\begin{array}{l}\text { Miniopterus } \\
\text { fuliginosus }\end{array}$ & Japan & LC326397 & LC326399 & - \\
\hline SD044 & Eptesicus serotinus & China & MH393943 & MH393931 & - \\
\hline TryCC 1087 & Sturnira lillium & Goiás/BR & - & - & FJ900253 \\
\hline TryCC 1314 & Sturnira lillium & Paraná/BR & - & - & FJ900254 \\
\hline TryCC 1059 & Eptesicus brasiliensis & Tocantins/BR & - & - & FJ900252 \\
\hline TryCC 211 & Eptesicus brasiliensis & São Paulo/BR & - & - & FJ900249 \\
\hline TryCC 454 & Desmodus rotundus & $\begin{array}{c}\text { Mato Grosso do } \\
\text { Sul/BR }\end{array}$ & - & - & FJ900250 \\
\hline TryCC 495 & Carollia perspicillata & Roraima/BR & - & - & FJ900251 \\
\hline TryCC 1110 & Carollia perspicillata & São Paulo/BR & - & - & FJ002263 \\
\hline 272 & Carollia perspicillata & Guacharos/BO & - & - & JN651290 \\
\hline 274 & Carollia perspicillata & Guacharos/BO & - & - & JN651291 \\
\hline \multicolumn{6}{|l|}{ T. erneyi } \\
\hline TCC 1293 & Tadarida sp. & Chupanga/MZ & JN040987 & JN040964 & JN040956 \\
\hline TCC 1936 & Mops condylurus & Chupanga/MZ & - & - & JN040960 \\
\hline \multicolumn{6}{|l|}{ T. c. marinkellei } \\
\hline TCC 344 & Carollia perspicillata & Rondonia/BR & FJ001664 & GQ140360 & KT327330 \\
\hline TCC 501 & Carollia perspicillata & Rondonia/BR & FJ001665 & GQ140361 & JN543702 \\
\hline \multicolumn{6}{|l|}{ T.c. cruzi } \\
\hline TryCC 793 & Myotis levis & São Paulo/BR & FJ900241 & GQ140358 & - \\
\hline TryCC 507 & Carollia perspicillata & Amazonas/BR & FJ900240 & GQ140352 & FJ002256 \\
\hline TCC1994 & Myotis levis & São Paulo/BR & - & - & KT327329 \\
\hline \multicolumn{6}{|l|}{ T. rangeli } \\
\hline TCC 643 & Platyrrhinus lineatus & $\begin{array}{c}\text { Mato Grosso do } \\
\text { Sul/BR }\end{array}$ & FJ900242 & GQ140364 & - \\
\hline TryCC 643 & Platyrrhinus lineatus & $\begin{array}{l}\text { Mato Grosso do } \\
\text { Sul/BR }\end{array}$ & - & - & JN040963 \\
\hline \multicolumn{6}{|l|}{ T. vespertilionis } \\
\hline P14 & $\begin{array}{l}\text { Pipistrellus } \\
\text { pipistrellus }\end{array}$ & England & AJ009166 & AJ620283 & - \\
\hline
\end{tabular}




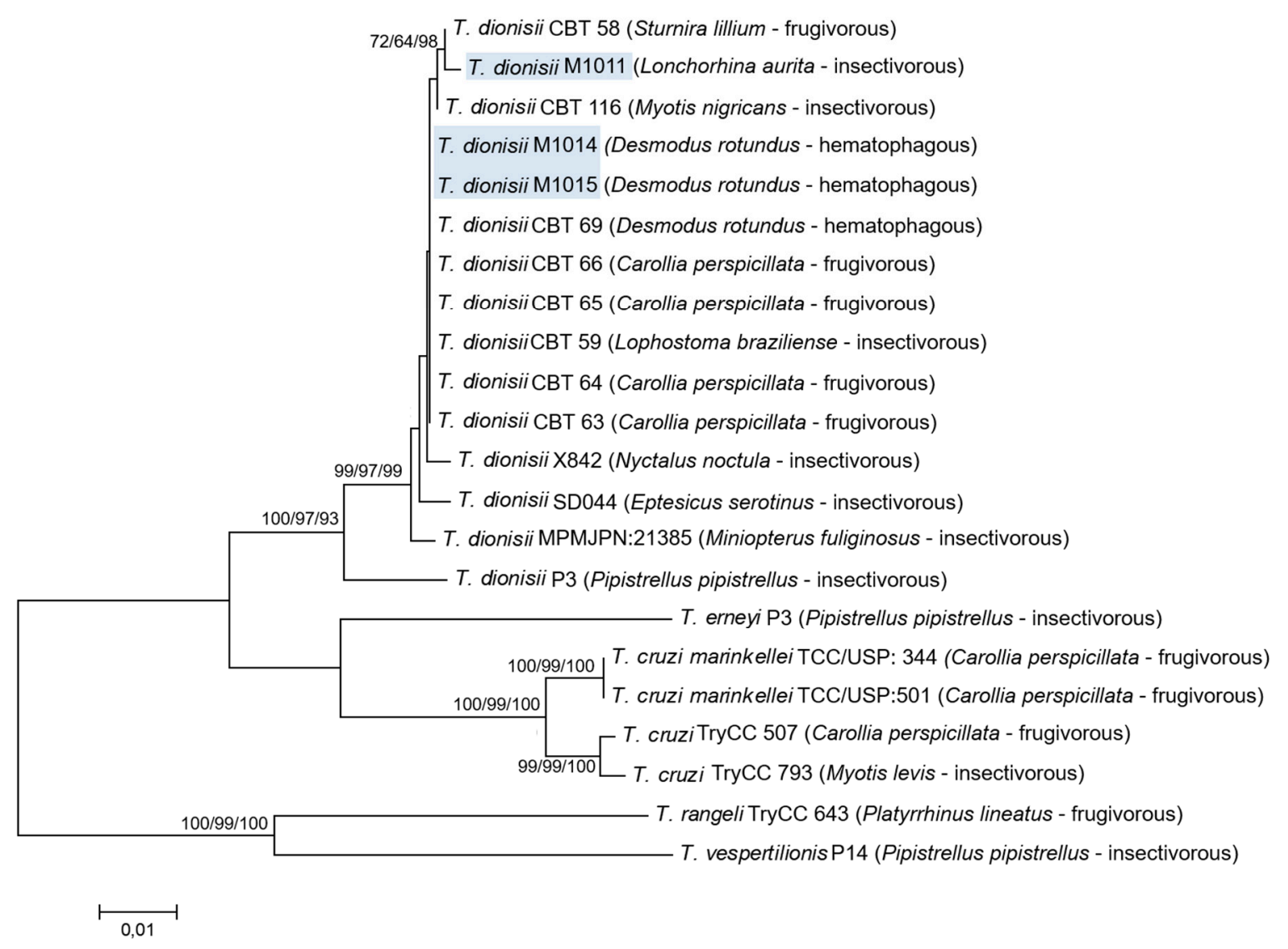

Figure 2. Concatenated phylogenetic tree from combined $18 \mathrm{~S}$ rDNA and $g$ GAPDH data sets (1153 characters) from 12 reference sequences of Trypanosoma dionisii and other sequences from the genus Trypanosoma. The tree was inferred by using the neighbor-joining (NJ), maximum likelihood (ML), methods and Bayesian inference (BI) based on the Kimura 2-parameter model. Bootstrap test results are shown next to the branches (NJ/ML/BI). Outgroup: Trypanosoma rangeli and Trypanosoma vespertilionis. GenBank accession numbers are shown in Table 1.

Estimates of evolutionary divergence of V7V8 18S rDNA, gGAPDH, and Cytb nucleotide sequences revealed that $T$. dionisii from the hematophagous bats (M1014 and M1015) were genetically similar. Comparing 18S rDNA, gGAPDH, and Cytb sequence divergence among the three isolates M1011, M1014, and M1015, the genetic distances obtained were $0.4 \%, 1.1 \%$, and $6 \%$ for $18 \mathrm{~S}$ rDNA, gGAPDH, and $C y t b$ sequences, respectively.

\subsection{Random Amplified Polymorphic DNA (RAPD)}

The dendrogram shows that the three isolates grouped together in a branch separated from the reference samples, but once more, this clade presented two clear branches: one containing isolates from D. rotundus (M1014 and M1015) and the other the isolate from L. aurita (M1011), supporting the existence of two subgroups (Supplementary Figure S3).

\section{Discussion}

The interest in identifying differences among isolates of the same species of trypanosome began with the discovery of T. c. cruzi and its life cycle by Carlos Chagas [29]. To date, most of these studies have concentrated on the T. c. cruzi and T. rangeli species, as high morphological, biological, biochemical, and molecular variability has been observed in these species $[30,31]$. Studies regarding differences among $T$. dionisii isolates are scarce, and most recent publications have focused solely on the molecular identification of this parasite in both hosts and vectors from Brazil and some other 
countries [7,8,10-12,18]. The three isolates of T. dionisii investigated (M1011, M1014, and M1015) were obtained in a study in different municipalities of Rio de Janeiro, where 22 samples of trypanosomatids were isolated by hemoculture of 84 bats [32]. Three samples were characterized as T. dionisii and 19 as T. madeirae [33]. Interestingly, we observed that T. dionisii and T. madeirae [33] were present in the same colony and were infecting the same bat species, Desmodus rotundus (data not shown). However, although co-infection is common among bats in nature, it was not detected in this study, probably because the isolation and amplification methods used for the culture of parasites exert a selective force, owing to which mixed infections are not frequently detected.

The classic identification of trypanosomatid protozoans depends on their isolation and subsequent in vitro maintenance; although it is a critical process, it enables morphological, biological, biochemical, and molecular analysis. In this study, the isolation in culture medium allowed the characterization of the three samples as $T$. dionisii using a DNA barcoding approach with three different molecular markers: V7V8 18S rDNA [34], gGAPDH [35], and Cytb [36]. To the best of our knowledge, this is the first report of $T$. dionisii infecting Lonchorhina aurita, an insectivorous bat.

The integrative methodologies used in this study were in agreement regarding of the overall result that the isolates from $D$. rotundus were similar to each other and different to the isolate from L. aurita and support the clear separation of the three isolates into two subgroups. T. dionisii sequences exhibited two different profiles. According to the phylogenetic analysis, the sequences obtained from the molecular targets for the M1011 samples showed greater similarity with $T$. dionisii sequences obtained from insectivorous (Myotis nigricans) and frugivorous (Sturnira lilium) bats. With regard to the M1014 and M1015 isolates, the sequences obtained in this study showed greater similarity with T. dionisii sequences obtained from hematophagous (D. rotundus) and frugivorous (Carollia perspicillata and Lophostoma brasiliense) bats. It was not possible to determine any type of association on subgroups of T. dionisii and feeding habits from the information obtained from phylogenetic analysis. Hamilton et al. [28] demonstrated in a previous study which used phylogenetic analysis using 18S rRNA and $g G A P D H$ sequences, clustered T. dionisii group A contained sequences from Europe only, and group B contained sequences from Europe and South America.

Phylogenetic analysis also confirmed that $T$. dionisii sequences from isolates obtained from hemathophagous and insectivorous bats were more similar to T. c. cruzi and T. cruzi marinkellei and closely related to T. erneyi, all species of the Schizotrypanum subgenus (Figure 2 and Supplementary Figure S2). Hamilton et al. [37] evaluated the relationships among T. c. cruzi, T. cruzi marinkellei, T. dionisii, and other species that comprise a single clade (clade T. cruzi), providing an interesting link between bats and T. cruzi evolution [26,38].

By multilocus enzyme electrophoresis (MLEE), random amplified polymorphic DNA (RAPD), and molecular sequencing, we found that the T. dionisii samples showed two different profiles, with samples M1014 and M1015 exhibiting the same profile and sample M1011 presenting a completely different one. Cavazzana et al. [4] demonstrated that there is only a $0.47 \%$ divergence in V7V8 of $18 \mathrm{~S}$ DNA sequences from Brazilian T. dionisii isolates, and $2 \%$ divergence with T. dionisii from Europe [4].

Morphological analysis using light microscopy showed differences among the M1011, M1014, and M1015 samples, which were later confirmed with morphometric analysis. Another observed difference was that the isolates M1014 and M1015, naturally contained a higher percentage of trypomastigote forms compared to that of the isolate M1011. A blood smear test was also performed for the three samples, however, it was negative for all of them. Thus, it was not possible to compare the morphology of the parasites in axenic culture with parasites in blood smear.

Cimicids, the only recognized vectors of $T$. dionisii, have not been described in the state of Rio de Janeiro, however, we cannot confirm its absence. It is worth mentioning that $T$. dionisii has already been found in species of triatomines that could play a role in the transmission of this parasite, mainly through the oral route [17]. In this study, despite the three bats being from the same locality but different colonies, they could have been exposed to different vectors. In addition, numerous other vectors are involved in the transmission of different Trypanosoma species, including fleas [39], flies [40], 
sandflies [41], and triatomines [42]. It is not yet known which vectors are associated with bats and possibly act as disseminators of trypanosomatids that infect these animals. Both sandflies [43] and triatomines [44] are parasited by trypanosomatids that use bats as a host. Cave-type triatomines (Cavernicola pilosa and Cavernicola lenti) are described as possible vectors of some Schizotrypanum species, such as T. cruzi marinkellei [45]. An alternative possibility of direct transmission of T. dionisii among bats in this region should be considered due to their habit of aggregating into colonies [16]. The isolate M1011 was isolated from the insectivorous bat L. aurita, described as having cave-dwelling and colony-forming habits [46]. In a captive study, Thomas et al. [47] demonstrated that bats can be infected by different species of trypanosomes orally via the ingestion of triatomines as well as through contamination when exposed to the feces and urine of these insects or through bites.

Due to little information available regarding the host specificity of most trypanosomes, the diversity of trypanosomes may have been considerably over- or underestimated with respect to their choice of host [28]. T. dionisii, previously believed to infect only bats and cimids, has been described in other mammalian hosts and vectors $[17,18]$. Therefore, a restricted association with its hosts cannot be guaranteed for any species of Trypanosoma. This leads us to question whether heterogeneity among isolates within the same species has to do with the adaptation to different hosts and if it is of medical importance to humans. To understand the true variability between $T$. dionisii isolates, studies integrating morphology, biology and molecular biology must be performed with isolates from different bat species and different locations.

\section{Materials and Methods}

\subsection{Isolation and Light Microscopy of Samples}

Samples were isolated from hemocultures from two hematophagous bats, D. rotundus (M1014 and M1015), and one insectivorous bat, L. aurita (M1011), which were caught in the municipal district of Miracema in Rio de Janeiro in 2007. All bat captures and blood collections were performed in association with the Bat Maintenance Program conducted by researchers from the Rio de Janeiro State Agricultural Research Corporation (PESAGRO-RIO). The bats were captured in wild and peri-urban areas at pre-established locations, such as near corrals, water shackles, basements, or natural bat shelters, employing mist-nets that were equipped at dusk. The captured bats were carefully removed from the nets and classified according to family, gender, and clinical appearance. For blood collection, the animals were anesthetized with ketamine at a concentration calculated according to body mass, and up to $1 \mathrm{~mL}$ of blood was collected via cardiac puncture. Afterward, the animals were identified with a collar and released at the same capture site [32].

The flagellated protozoa were isolated and maintained in biphasic medium NNN (Novy, McNeal, Nicolle) with Schneider and supplemented with $10 \%$ fetal bovine serum at $26-28^{\circ} \mathrm{C}$. The cultures were monitored weekly for 30 days. In all experiments, the three isolates were in the same passage in the axenic culture medium described above.

\subsection{Parasite Morphology and Induction of Metacyclogenesis}

Light microscopy was performed on Giemsa-stained smears using M1011, M1014, and M1015 parasites from culture with NNN and Schneider medium supplemented with $10 \%$ fetal bovine serum by three, 10, and 17 days. Additionally, epimastigote forms of the M1011 isolate were transferred at 1 $\times 10^{6}$ parasites $/ \mathrm{mL}$ into Roswell Park Memorial Institute (RPMI) medium with $5 \%$ fetal calf serum at $\mathrm{pH} 8.0$ for differentiation and acquisition of trypomastigote forms, following a protocol described by Koerich et al. [48]. The percentage of trypomastigote forms was determined by counting 100 randomly selected forms on the slides. Analyses were carried out under optical microscopy at 1000x magnification by examining the characteristics of the culture forms. All the experiment was performed in triplicate. 
Measurements of the parasites $(\mu \mathrm{m})$ were taken for both the total length of the cell body and the free flagellum of 20 randomly selected parasites. Photomicrographs were obtained using Motic Image Plus 2.0 software with the optical microscope Nikon Eclipse E200. Statistical analysis was performed to compare the values of body and flagellum measurements of M1011 and M1014 samples using a one-way ANOVA test. The null hypothesis for the test was that the two means were equal, and a comparison of means whose alpha decision level was equal to or less than 0.05 was used.

\subsection{Multilocus Enzyme Electrophoresis (MLEE)}

The isoenzyme electrophoresis technique was used in accordance with the protocols described by Cupolillo et al. [49]. Nine enzymatic systems were analyzed; nucleotidase (NH), phosphoglucomutase (PGM), mannose phosphate dehydrogenase (MPI), 6-phosphogluconate dehydrogenase (6PGDH), malic enzyme (ME), glucose phosphate isomerase (GPI), glucose-6-phosphate dehydrogenase (G6PDH), malate dehydrogenase (MDH), and isocitrate dehydrogenase (IDH). The electrophoretic mobility of the isolates was compared to the reference samples; T. c. cruzi DTUs TcII and TcVI (Y and CL strains, respectively), Trypanosoma rangeli (Choachi strain), and Trypanosoma desterrensis [50].

\subsection{Polymerase Chain Reaction (PCR) Assays}

PCR assays were performed using DNA extracted from cultured trypanosomes. Approximately $20 \mathrm{~mL}$ of culture were centrifuged and washed twice in sterile phosphate buffer saline (1 M; pH 7.2) to pellet the cells, and DNA was extracted using DNAzol kit (Invitrogen, USA) according to the manufacturer's instructions.

PCR amplification of V7V8 18S rDNA was performed to amplify an approximately a $900 \mathrm{bp}$ fragment under conditions described by Marcili et al. [34]. The $g G A P D H$ gene from the isolates was amplified using primers G1/G2 (900 bp), as described by Hamilton et al. [35]. The primers used to amplify Cytb gene region encoded in the maxicircle DNA of the mitochondrial genome were P18/P20 (500 bp) [36]. In all assays, water was used as negative control and DNA from T. c. cruzi DTU TcII (Y strain) as a positive control. The PCR products were purified using the QIAquick Purification Kit (Qiagen, Manchester, UK) to prepare them for sequencing.

\subsection{Sequencing Analysis}

All nucleotide sequences were determined using an automatic sequencer (3730 DNA Analyzer, Applied Biosystems) and analyzed using the Basic Local Alignment Search Tool (BLAST) program (http://blast.ncbi.nlm.nih.gov/Blast.cg). All nucleotide sequences obtained for each molecular target (V7V8 18S rDNA, $g$ GAPDH, and Cytb) were aligned and compared using the Molecular Evolutionary Genetics Analysis (MEGA) program version 7.0.26 [51] with bat trypanosome species and other trypanosomatids available from GenBank (https:/www.ncbi.nlm.nih.gov/pmc/articles/PMC540017/).

The concatenated alignment V7V8 18S rDNA and gGAPDH results were analyzed by neighbor-joining (NJ), maximum likelihood (ML), and Bayesian (B) methods using Kimura 2-parameter model with gamma distributed rate variation. To evaluate the robustness of the nodes in the resulting phylogenetic tree for NJ and ML methods, 1000 bootstrap replications were performed using MEGA version 7.0.26 [52]. The models of sequence evolution and their parameters were calculated using the jModelTest in MEGA version 7.0.26 [52]. Bayesian inference (BI) was run in MrBayes (version 3.1.1) [53] with a Kimura 2-parameter model with gamma distributed rate variation. The runs converged after $1,000,000$ generations and discarding the first $25 \%$ of the trees as burn-in. Phylogenetic tree inferred by Maximum likelihood with the Tamura-Nei model of partial sequences of $C y t b$ genes of $T$ dionisii from this study and reference sequences deposited in GenBank were aligned with the MEGA program version 7.0.26 [53]. Sequences of bat trypanosomes from this study, the species included in the phylogenetic trees and their respective host, geographical origin, and GenBank accession numbers are shown in Table 1. 


\subsection{Random Amplified Polymorphic DNA (RAPD)}

The genetic variability among isolates was assessed by random DNA amplification using four arbitrary sequence primers with 10 nucleotides (Pharmacia Biothec Ready-To-Go ${ }^{\mathrm{TM}}$ RAPD Analysis $\mathrm{Kit})$, according to the manufacturer's recommendations. The amplified products were analyzed on an agarose gel $(2 \%)$, stained with ethidium bromide, and visualized under ultraviolet light. The RAPD profiles were analyzed using the Jaccard similarity coefficient to determine the proportion of similar pieces among all isolates. The matrix was transformed into a dendrogram by an unweighted method of grouping in pairs using the arithmetic mean (unweighted pair group method using arithmetic averages (UPGMA)) [54]. Numerical analysis was performed using the NTSYS-pc software program (Version1.70, Exeter software).

Supplementary Materials: The following are available online at http://www.mdpi.com/2076-0817/9/9/736/s1, Figure S1: Schematic representation of the isoenzyme patterns for glucose phosphate isomerase (GPI), malate dehydrogenase (MDH), isocitrate dehydrogenase (IDH), malic enzyme (ME). A-Trypanosoma rangeli (Choachi), B and C-Trypanosoma c. cruzi (Y, CL Brener), D-Trypanosoma desterrensis, E, F and G-Trypanosoma dionisii (M1011, M1014, M1015). Figure S2: Phylogenetic analyses demonstrating the clear separation of Trypanosoma dionisii isolates into two groups. Phylogenetic tree inferred by Maximum likelihood with the Tamura-Nei model of partial sequences of cytochrome $b$ genes of $T$ dionisii from this study and reference sequences deposited in GenBank were aligned with the Molecular Evolutionary Genetics Analysis (MEGA) program version 7.0.26. Outgroup: Trypanosoma rangeli. Bootstrap test results (1000 replicates) are shown next to the branches GenBank accession numbers are shown in Table 1. Figure S3: Unweighted pair group method using arithmetic averages (UPGMA) dendrogram built with the simple matching coefficient of similarity based on the genetic profiles obtained from Random Amplified Polymorphic (RAPD) among isolates. T. dionisii M1011 was clustered separated M1014 and M1015 samples. T. c. cruzi Y, T. cruzi ClBrenner, T. rangeli Choachi and T. desterrensis were used as reference and were clustered totally separated of the T. dionisii samples. Table S1: The sequence analysis of DNA products obtained with the three molecular targets in comparison with DNA sequences of Trypanosoma spp. deposited in GenBank confirmed the identification of the three isolates as Trypanosoma dionisii. Graphic S1: Body and flagellum measurements of parasites used in morphometric analysis. A. M1011, B. M1014.

Author Contributions: Conceptualization, J.H.d.S.B. and M.d.F.M.; formal analysis, J.H.d.S.B., H.K.T., and M.d.F.M.; funding acquisition, J.H.d.S.B. and M.d.F.M.; investigation, J.H.d.S.B. and M.d.F.M.; methodology, J.H.d.S.B., A.L.R.R., S.C.d.C.X., K.C.S.N., H.K.T., and M.d.F.M.; project administration and supervision, M.d.F.M.; writing-original draft J.H.d.S.B.; writing,-review and editing, J.H.d.S.B., A.L.R.R., S.C.d.C.X., K.C.S.N., H.K.T., and M.d.F.M. All authors have read and agreed to the published version of the manuscript.

Funding: This research received no external funding.

Acknowledgments: We are grateful to Fabiola Roman for the support with the construct the concatenated phylogenetic tree and in the bayesian analysis. We thank the Genomic Platform-DNA Sequencing (PDTIS-Fiocruz) for supporting the sequencing of the samples in this study.

Conflicts of Interest: The authors declare no conflict of interest.

\section{References}

1. Lukes, J.; Butenko, A.; Hashimi, H.; Maslov, D.A.; Votypka, J.; Yurchenko, V. Trypanosomatids are much more than just trypanosomes: Clues from the expanded family tree. Trends Parasitol. 2018, 34, 466-480. [CrossRef] [PubMed]

2. Maslov, D.A.; Opperdoes, F.R.; Kostygov, A.Y.; Hashimi, H.; Lukeš, J.; Yurchenko, V. Recent advances in trypanosomatid research: Genome organization, expression, metabolism, taxonomy and evolution. Parasitology 2019, 146, 1-27. [CrossRef] [PubMed]

3. Baker, J.R.; Greens, S.M.; Chalonel, L.A.; Gabora, K.M. Trypanosoma (Schizotrypanum) dionisii of Pipistrellus pipistrellus (Chiroptera): Intra- and extracellular development in vitro. Parasitology 1972, 65, 251-263. [CrossRef] [PubMed]

4. Cavazzana, M.; Marcili, A.; Lima, L.; Maia da Silva, F.;Junqueira, A.C.; Veludo, H.H.; Viola, L.B.; Campaner, M.; Nunes, V.L.; Paiva, F.; et al. Phylogeographical, ecological and biological patterns shown by nuclear (SSU rRNA and $g G A P D H)$ and mitochondrial $(C y t b)$ genes of trypanosomes of the subgenus Schizotrypanum parasitic in Brazilian bats. Int. J. Parasitol. 2010, 40, 345-355. [CrossRef] 
5. García, L.; Ortíz, S.; Osorio, G.; Torrico, M.C.; Torrico, F.; Solari, A. Phylogenetic analysis of Bolivian bat trypanosomes of the subgenus Schizotrypanum based on cytochrome $b$ sequence and minicircle analyses. PLOS ONE 2012, 7, e36578. [CrossRef]

6. Hodo, C.L.; Goodwinb, C.C.; Mayes, B.C.; Mariscal, J.A.; Waldrupd, K.A.; Hamer, A.S. Trypanosome species including Trypanosoma cruzi in sylvatic and peridomestic bats of Texas. Acta Trop. 2016, 164, 259-266. [CrossRef]

7. Mafie, E.; Rupa, F.H.; Takano, A.; Suzuki, K.; Maeda, K.; Sato, H. First record of Trypanosoma dionisii of the T. cruzi clade from the Eastern bent-winged bat (Miniopterus fuliginosus) in the Far East. Parasitol. Res. 2018, 117, 673-680. [CrossRef]

8. Wang, L.J.; Han, H.J.; Zhao, M.; Liu, J.W.; Luo, L.M.; Wen, H.L.; Qin, X.R.; Zhou, C.M.; Qi, R.; Yu, H.; et al. Trypanosoma dionisii in insectivorous bats from northern China. Acta Trop. 2019, 193, 124-128. [CrossRef]

9. Linhart, P.; Band'ouchová, H.; Zukal, J.; Votypka, J.; Kokurewicz, T.; Dundarova, H.; Apoznanski, G.; Heger, T.; Kubickova, A.; Nemcova, M.; et al. Trypanosomes in Eastern and Central European bats. Acta Vet. Brno 2020, 89, 69-78. [CrossRef]

10. Dario, M.A.; Lisboa, C.V.; Costa, L.M.; Morateli, R.; Nascimento, M.P.; Costa, L.P.; Leite, Y.L.R.; Llewellyn, M.S.; Xavier, S.C.C.; Roque, A.L.R.; et al. High Trypanosoma spp. diversity is maintained by bats and triatomines in Espírito Santo state, Brazil. PLoS ONE 2017, 12, e0188412. [CrossRef]

11. Santos, F.C.B.; Lisboa, C.V.; Xavier, S.C.C.; Dario, M.A.; Verde, R.S.; Calouro, A.M.; Roque, A.L.R.; Jansen, A.M. Trypanosoma sp. diversity in Amazonian bats (Chiroptera; Mammalia) from Acre State, Brazil. Parasitology 2018, 145, 828-837. [CrossRef] [PubMed]

12. Bento, E.C.; Gómez-Hernández, C.; Batista, L.R.; Anversa, L.; Pedrosa, A.L.; Lages-Silva, E.; Ramírez, J.D.; Ramirez, L.E. Identification of bat trypanosomes from Minas Gerais state, Brazil, based on 18S rDNA and Cathepsin-L-like targets. Parasitol. Res. 2018, 117, 737-746. [CrossRef] [PubMed]

13. Lourenço, J.L.M.; Minuzzi-Souza, T.T.C.; Silva, L.R.; Oliveira, A.C.; Mendonça, V.J.; Nitz, N.; Aguiar, L.M.S.; Gurgel-Gonçalves, R. High frequency of trypanosomatids in gallery forest bats of a Neotropical savanna. Acta Trop. 2018, 177, 200-206. [CrossRef] [PubMed]

14. Hoare, C.A. The Trypanosomes of mammals. In A Zoological Monograph; Blackweel Scientific Publications: Oxford/Edinburg, UK, 1972; pp. 327-400.

15. Gardner, R.A.; Molyneux, D.H. Schizotrypanum in British bats. Parasitology 1988, 97, 43-50. [CrossRef] [PubMed]

16. Molyneux, D.H. Trypanosomes of bats. In Parasitprotoz; Kreier, J.P., Baker, J.R., Eds.; Academic Press: Cambridge, MA, USA, 1991; pp. 195-224.

17. Dario, M.A.; Rodrigues, M.S.; Barros, J.H.S.; Xavier, S.C.C.; D'Andrea, O.S.; Roque, A.L.R.; Jansen, A.M. Ecological scenario and Trypanosoma cruzi DTU characterization of a fatal acute Chagas disease case transmitted orally (Espírito Santo state, Brazil). Parasite Vector 2016, 9, 477. [CrossRef]

18. Rodrigues, M.S.; Lima, L.; Xavier, S.C.C.; Herrera, H.M.; Rocha, F.L.; Roque, A.L.R.; Teixeira, M.M.G.; Jansen, A.M. Uncovering Trypanosoma spp. diversity of wild mammals by the use of DNA from blood clots. Int. J. Parasitol. Parasites Wildl. 2019, 8, 171-181. [CrossRef]

19. Maeda, F.Y.; Cortez, C.; Alves, R.M.; Yoshida, N. Mammalian cell invasion by closely related Trypanosoma species T. dionisii and T. cruzi. Acta Trop. 2012, 121, 141-147. [CrossRef]

20. Baker, J.R.; Thompson, G.B. Two species of Trypanosoma from British bats. Trans. R. Soc. Trop. Med. Hyg. 1971, 65, 427. [CrossRef]

21. Wilkins, S.R.; Baker, J.R. Proceedings: Limited survival of Trypanosoma (Schizotrypanum) dionisii in Rhodnius prolixus. Trans. R. Soc. Trop. Med. Hyg. 1975, 69, 433.

22. Thorne, K.J.; Glauert, A.M.; Svvennsen, R.J.; Thomas, H.; Morris, J.; Franks, D. Evasion of the oxidative microbicidal activity of human monocytes by trypomastigotes of Trypanosoma dionisii. Parasitology 1981, 83, 115-123. [CrossRef]

23. Glauert, A.M.; Baker, J.R.; Selden, L.F. Mechanism of entry and development of Trypanosoma dionisii in non-phagocytic cells. J. Cell Sci. 1982, 56, 371-378. [PubMed]

24. Petry, K.; Schottelius, J.; Baltz, T. Purification of metacyclic trypomastigotes of Trypanosoma cruzi and Trypanosoma dionisii from culture using an epimastigote-specific monoclonal antibody. Parasitol. Res. 1987, 73, 224-227. [CrossRef] [PubMed] 
25. Rangel, D.A.; Lisboa, C.V.; Novaes, R.L.M.; Silva, B.A.; Souza, R.F.; Jansen, A.M.; Moratelli, R.; Roque, A.L. Isolation and characterization of trypanosomatids, including Crithidia mellificae, in bats from the Atlantic Forest of Rio de Janeiro, Brazil. PLoS Negl. Trop. Dis. 2019, 13, e0007527. [CrossRef] [PubMed]

26. Lima, L.; Maia da Silva, F.; Neves, L.; Attias, M.; Takata, C.S.A.; Campaner, M.; Souza, W.; Hamilton, P.B.; Teixeira, M.M. Evolutionary insights from bat trypanosomes: Morphological developmental and phylogenetic evidence of a new species Trypanosoma (Schizotrypanum) erneyi sp nov in african bats closely related to Trypanosoma (Schizotrypanum) cruzi and Allied Species. Protist 2012, 163, 856-872. [CrossRef] [PubMed]

27. Acosta, I.C.L.; Da Costa, A.P.; Gennari, S.M.; Marcili, A. Survey of Trypanosoma and Leishmania in wild and domestic animals in an Atlantic rainforest fragment and surroundings in the state of Espírito Santo, Brazil. J. Med. Entomol. 2014, 51, 686-693. [CrossRef]

28. Hamilton, P.B.; Cruickshank, C.; Stevens, J.R.; Teixeira, M.M.; Mathews, F. Parasites reveal movement of bats between the New and Old Worlds. Mol. Phylogenet. Evol. 2012, 63, 521-526. [CrossRef]

29. Chagas, C. Nova tripanozomiaze humana. Estudos sobre a morfolojia e o ciclo evolutivo do Schizotrypanum cruzi n. gen, n. sp.; ajente etiolojico de nova entidade morbida do homem. Mem. Inst. Oswaldo Cruz. 1999, 1, 11-80. [CrossRef]

30. Ortiz, S.; Zulantay, I.; Apt, W.; Saavedra, M.; Solari, A. Transferability of Trypanosoma cruzi from mixed human host infection to Triatoma infestans and from insects to axenic culture. Parasitol. Int. 2015, 64, 33-36. [CrossRef]

31. Dorn, P.L.; Mcclure, A.G.; Gallaspy, M.D.; Waleckx, E.; Woods, A.S.; Monroy, M.C.; Stevens, L. The diversity of the Chagas parasite Trypanosoma cruzi infecting the main Central American vector Triatoma dimidiata from Mexico to Colombia. PLoS Negl. Trop. Dis. 2017, 11, e0005878. [CrossRef]

32. Barros, J.H.S.; Romijn, P.C.; Baptista, C.; Pinto, A.G.S.; Madeira, M.F. Relato da infecção natural de morcegos por flagelados tripanosomatídeos em diferentes municípios do Estado do Rio de Janeiro. Rev. Soc. Bras. Med. Trop. 2008, 41, 683-685. [CrossRef]

33. Barros, J.H.S.; Lima, L.; Schubach, A.O.; Teixeira, M.M.G. Trypanosoma madeirae sp. n.; A species of the clade T. cruzi associated with the neotropical common vampire bat Desmodus rotundus. Int. J. Parasitol. Parasites Wildl. 2019, 8, 71-81. [CrossRef] [PubMed]

34. Marcili, A.; Costa, A.P.; Soares, H.S.; Acosta, C.; De Lima, J.T.; Minervino, A.H.; Melo, A.T.; Aguiar, D.M.; Pacheco, R.C.; Gennari, S.M. Isolation and phylogenetic relationships of bat trypanosomes from different biomes in Mato Grosso, Brazil. J. Parasitol. 2013, 99, 1071-1076. [CrossRef]

35. Hamilton, P.B.; Stevens, J.R.; Gaunt, M.W.; Gidley, J.; Gibson, W.C. Trypanosomes are monophyletic, evidence from genes for glyceraldehyde phosphate dehydrogenase and small subunit ribosomal RNA. Int. J. Parasitol. 2004, 34, 1393-1404. [CrossRef] [PubMed]

36. Marcili, A.; Lima, L.; Valente, V.C.; Valente, S.A.; Batista, J.S.; Junqueira, A.C.; Souza, A.I.; da Rosa, J.A.; Campaner, M.; Lewis, M.D.; et al. Comparative phylogeography of Trypanosoma cruzi TCIIc, new hosts association with terrestrial ecotopes and spatial clustering. Infect. Genet. Evol. 2009, 9, 1265-1274. [CrossRef] [PubMed]

37. Hamilton, P.B.; Teixeira, M.M.G.; Stevens, J.R. The evolution of Trypanosoma cruzi: The "bat seeding" hypothesis. Trends Parasitol. 2012, 28, 136-141. [CrossRef] [PubMed]

38. Ramírez, J.D.; Tapia-Calle, G.; Muñoz-Cruz, G.; Poveda, C.; Rendón, L.M.; Hincapié, E.; Guhl, F. Trypanosome species in neo-tropical bats: Biological evolutionary and epidemiological implications. Infec. Genet. Evol. 2014, 22, 250-256. [CrossRef]

39. Smith, A.; Telfer, S.; Burthe, S.; Bennett, M.; Begon, M. Trypanosomes, fleas and field voles, ecological dynamics of a host-vector-parasite interaction. Parasitology 2005, 3, 355-365. [CrossRef]

40. Geiger, A.; Ravel, S.; Mateille, T.; Janelle, J.; Patrel, D.; Cuny, G.; Frutos, R. Vector competence of Glossina palpalis gambiensis for Trypanosoma bruceis. 1. and genetic diversity of the symbiont Sodalis glossinidius. Mol. Biol. Evol. 2007, 24, 102-109. [CrossRef]

41. Bates, P.A. Leishmania sand fly interaction, progress and challenges. Curr. Opin. Microbiol. 2008, 11, 340-344. [CrossRef]

42. Shofield, C.J. Trypanosoma cruzi-The vectos-parasite paradox. Memb. Inst. Oswaldo Cruz. 2000, 95, 535-544. [CrossRef] [PubMed] 
43. Lampo, M.; Feliciangeli, M.D.; Márques, L.M.; Bastidas, C.; Lau, P. A possible role of bats as a blood source for the Leishmania vector Lutzomyia longipalpis (Diptera, Psychodidae). Am. J. Trop. Med. Hyg. 2000, 62, 718-719. [CrossRef] [PubMed]

44. Assis, G.F.M.; Azeredo, B.V.M.; Fuente, A.L.C.; Diotaiuti, L.; Lana, M. Domiciliation of Triatoma pseudomaculata (Corrêa e Espínola 1964) in the Jequitinhonha valley, State of Minas Gerais. Rev. Soc. Bras. Med. Trop. 2007, 40, 391-396. [CrossRef]

45. Marinkelle, C.J. Developmental stages of Trypanosoma cruzi-like flagellates in Cavernicola pilosa. Rev. Biol. Trop. 1982, 30, 107-111. [PubMed]

46. Leal, E.S.B.; Gomes-Silva, F.F.; Filho, D.Q.G.; Júnior, S.M.A.; Neves, R.M.L.; Telino-Júnior, W.R. Update of the distribution of Lonchorhina aurita (Chiroptera), a vulnerable cave-dwelling bat in Brazil. Neotrop. Biol. Conserv. 2018, 13, 254-267. [CrossRef]

47. Thomas, M.E.; Rasweiler, J.J.; D’Alessandro, A. Experimental transmission of the parasitic flagellates Trypanosoma cruzi and Trypanosoma rangeli between triatomine bugs or mice and captive neotropical bats. Mem. Inst. Oswaldo Cruz. 2007, 102, 559-565. [CrossRef]

48. Koerich, L.B.; Emmanuelle-Machado, P.; Santos, K.; Grisard, E.C.; Steindel, M. Differentiation of Trypanosoma rangeli: High production of infective trypomastigote forms in vitro. Parasitol. Res. 2002, 88, 21-25. [CrossRef]

49. Cupolillo, E.; Grimaldi, G.; Mimen, H. A general classification of new world Leishmania using numeral zymotaxonomy. Am. J. Trop. Med. Hyg. 1994, 50, 296-311. [CrossRef]

50. Grisard, E.C.; Sturm, N.R.; Campbell, D.A. A new species of trypanosome Trypanosoma desterrensis sp. $\mathrm{n}$ isolated from South American bats. Parasitology 2003, 127, 265-271. [CrossRef]

51. Kumar, S.; Stecher, G.; Tamura, K. MEGA7: Molecular Evolutionary Genetics Analysis Version 7.0 for Bigger Datasets. Mol. Biol. Evol. 2015, 33, 1870-1874. [CrossRef]

52. Posada, D. jModelTest, phylogenetic model averaging. Mol. Biol. Evol. 2008, 25, 1253-1256. [CrossRef]

53. Ronquist, F.; Huelsenbeck, J.P. MrBayes 3: Bayesian phylogenetic inference under mixed models. Bioinformatics 2003, 19, 1572-1574. [CrossRef] [PubMed]

54. Schlee, D.; Sneath, P.H.A.; Sokal, R.R.; Freeman, W.H. Numerical Taxonomy. The Principles and Practice of Numerical Classification. Syst. Zool. 1975, 24, 263. [CrossRef] 